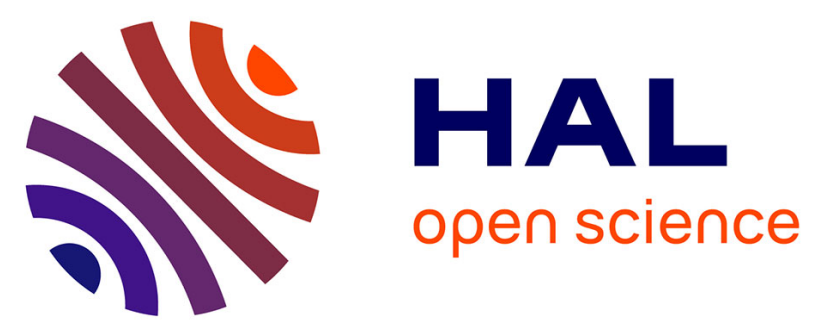

\title{
Changes in the management of urinary tract infections in women: impact of the new recommendations on antibiotic prescribing behavior in France, between 2014 and 2019
}

Arthur Piraux, Sébastien Faure, Kurt G Naber, Jakhongir F Alidjanov, Aline Ramond-Roquin

\section{To cite this version:}

Arthur Piraux, Sébastien Faure, Kurt G Naber, Jakhongir F Alidjanov, Aline Ramond-Roquin. Changes in the management of urinary tract infections in women: impact of the new recommendations on antibiotic prescribing behavior in France, between 2014 and 2019. BMC Health Services Research, 2021, 21 (1), pp.612. 10.1186/s12913-021-06653-4 . hal-03273582

\section{HAL Id: hal-03273582 \\ https://univ-angers.hal.science/hal-03273582}

Submitted on 29 Jun 2021

HAL is a multi-disciplinary open access archive for the deposit and dissemination of scientific research documents, whether they are published or not. The documents may come from teaching and research institutions in France or abroad, or from public or private research centers.
L'archive ouverte pluridisciplinaire HAL, est destinée au dépôt et à la diffusion de documents scientifiques de niveau recherche, publiés ou non, émanant des établissements d'enseignement et de recherche français ou étrangers, des laboratoires publics ou privés. 


\title{
Changes in the management of urinary tract infections in women: impact of the new recommendations on antibiotic prescribing behavior in France, between 2014 and 2019
}

Arthur Piraux ${ }^{1 *}$, Sébastien Faure ${ }^{1}$, Kurt G. Naber ${ }^{2}$, Jakhongir F. Alidjanov ${ }^{3}$ and Aline Ramond-Roquin ${ }^{4,5}$

\begin{abstract}
Background: Urinary tract infections (UTIs) are among the most common infections that require antibiotic therapy. In December 2015, new guidelines for UTI management were published in France with the aim of reducing antibiotic misuse and the risk of antimicrobial resistance.

Objectives: To analyze changes in antibiotic prescribing behavior for acute uncomplicated UTI in women in France from 2014 to 2019.

Methods: Retrospective study using data extracted from the medico-administrative database 'OpenMedic' that is linked to the French National Health Data System and collects data on the reimbursement of prescribed drugs. The analyses focused on the number of boxes of antibiotics delivered by community pharmacies, the molecule class, and the prescriber's specialty.
\end{abstract}

Results: Overall, antibiotic dispensing by community pharmacies increased by 2\% between 2014 and 2019, but with differences in function of the antibiotic class. The use of antibiotics recommended as first-line and second-line treatment increased ( $+41 \%$ for fosfomycin and $+7430 \%$ for pivmecillinam). Conversely, the dispensing of lomefloxacin and norfloxacin decreased by $80 \%$, and that of ciprofloxacin by $26 \%$. Some antibiotics were mostly prescribed by general practitioners (lomefloxacin, pivmecillinam) and others by secondary care physicians (ofloxacin). Dispensing increased for antibiotics prescribed by secondary care physicians (+ 13\% between 2014 and 2019) and decreased for antibiotics prescribed by GPs (- $2 \%$ for the same period).

Conclusion: These data suggest that the new recommendations are followed, as indicated by the increased prescription of fosfomycin and pivmecillinam and decreased prescription of fluoroquinolones. However, the efficient transmission and implementation of new recommendations by practitioners requires time, means and dedicated tools.

Keywords: Urinary tract infection, Antimicrobial resistance, Antibiotic consumption, Guideline adherence, Prescriberpharmacist collaboration, Educational intervention, Antibiotic resistance

\footnotetext{
* Correspondence: arthur.piraux@univ-angers.fr

'Univ Angers, Inserm, CNRS, MINT, SFR ICAT, 16 boulevard Daviers, F-49000 Angers, France

Full list of author information is available at the end of the article
}

(C) The Author(s). 2021 Open Access This article is licensed under a Creative Commons Attribution 4.0 International License, which permits use, sharing, adaptation, distribution and reproduction in any medium or format, as long as you give appropriate credit to the original author(s) and the source, provide a link to the Creative Commons licence, and indicate if changes were made. The images or other third party material in this article are included in the article's Creative Commons licence, unless indicated otherwise in a credit line to the material. If material is not included in the article's Creative Commons licence and your intended use is not permitted by statutory regulation or exceeds the permitted use, you will need to obtain permission directly from the copyright holder. To view a copy of this licence, visit http://creativecommons.org/licenses/by/4.0/ The Creative Commons Public Domain Dedication waiver (http://creativecommons.org/publicdomain/zero/1.0/) applies to the data made available in this article, unless otherwise stated in a credit line to the data. 


\section{Background}

Urinary tract infections (UTIs) are among the most common bacterial infections, particularly in women [13]. Yet, UTI incidence is difficult to estimate because this is not a reportable disease in many countries and in primary care settings the diagnosis may not be always confirmed by urine testing. Previous studies found that about $10 \%$ of $>18$-year-old women presented UTI symptoms in the 12 months preceding the survey, and that approximately $50 \%$ of women had at least one episode of cystitis during their life $[1,4]$. In France, 4 to 6 million people have UTI each year. It is one of the main reasons for consulting a general practitioner (GP) $[3,5,6]$.

UTIs, particularly acute uncomplicated cystitis, are usually treated with short-course antibiotic regimens. However, bacterial resistance to some antibiotics currently used for managing community-acquired UTIs has been detected in primary care settings and hospitals worldwide [7-9]. Antimicrobial resistance (AMR) is considered one of the most important threats to modern medicine by the World Health Organization (WHO) [8, $10,11]$. According to a recent WHO report, bacterial resistance has been found in almost $40 \%$ of human infections in some developed countries [12]. In the case of UTIs, antibiotic resistance is associated with delayed symptom resolution, and might cause pyelonephritis [13, 14]. Therefore, to limit AMR increase, recommendations on UTI management are regularly updated by the health authorities and scientific societies [7, 15, 16]. For instance, the current guidelines indicate that in women with uncomplicated UTI, fluoroquinolones (e.g. lomefloxacin and norfloxacin) should only be prescribed as last-line treatment $[15,17]$. In France, the Société de pathologie infectieuse de langue française (French infectious disease society) and the Haute autorité de la santé (French national health authority) updated their guidelines on UTI management in December 2015 and now recommend a single dose of fosfomycin for acute uncomplicated cystitis (Table 1). Moreover, to limit the use of lomefloxacin and norfloxacin, the French authorities decided to stop their reimbursement from June 2019. Additionally, several public health campaigns have been deployed to make people aware of AMR risk and to explain the correct use of antibiotics [10, 20-22].
The objective of this study was to analyze how antibiotic prescriptions for the management of acute uncomplicated UTI in women changed in France between 2014 and 2019 to determine whether and to what extent these new guidelines have been implemented. Indeed, to reduce AMR, it is important to study the impact of health policies, recommendations, and awareness campaigns on the physicians' prescribing behaviors.

\section{Method}

\section{Study design}

Retrospective study based on data extracted from a medico-administrative database linked to the Système National Interrégimes de l'Assurance Maladie (French National Health Insurance System).

\section{Choice of database}

The 'OpenMedic' database collects data from the Système National des données de santé (National Health Data System) and was selected because it provides exhaustive information on drugs (Anatomical Therapeutic Chemical, ATC, classification) dispensed by community pharmacies to the entire French population since 2014 [23]. This database, available online and with an open license, allows determining the origin of drug prescriptions presented to community pharmacies and investigating drug utilization in France (reimbursed and non-reimbursed drugs). These data are collected by the Caisse Nationale de l'Assurance Maladie (French National Health Insurance System), in charge of medication reimbursement in France.

\section{Choice of antibiotics}

Only data on antibiotics included in the 2015 guidelines on UTI management were selected from the 'OpenMedic' database (Table 1) $[3,7,19,24]$. Some of these antibiotics are only used for treating acute cystitis (fosfomycin, nitrofurantoin, and lomefloxacin), while others are prescribed for UTI management in general (pivmecillinam and norfloxacin) and also for other infection types (ciprofloxacin, ofloxacin and norfloxacin). To limit the lack of information on the indication in the database, only oral antibiotics were selected (ear and eye drops, and injectable forms were removed). All

Table 1 French guidelines for the treatment of acute uncomplicated cystitis

\begin{tabular}{|c|c|c|}
\hline & Before December 2015 [18] & From December $2015[7,19]$ \\
\hline First line & Fosfomycin as a single dose & Fosfomycin as a single dose \\
\hline Second line & $\begin{array}{l}\text { Nitrofurantoin for } 5 \text { days } \\
\text { Fluoroquinolone as single dose (ciprofloxacin, ofloxacin) } \\
\text { Fluoroquinolone } e^{a} \text { for } 3 \text { days (ciprofloxacin, lomefloxacin, norfloxacin, ofloxacin) }\end{array}$ & Pivmecillinam for 5 days \\
\hline Third line & & $\begin{array}{l}\text { Nitrofurantoin for } 5 \text { days } \\
\text { Fluoroquinolone }{ }^{a} \text { as single dose (ciprofloxacin, ofloxacin) }\end{array}$ \\
\hline
\end{tabular}


antibiotics dispensed by French pharmacies are only available as prescription drugs and not as over-thecounter drugs.

\section{Inclusion criteria and study variables}

As the OpenMedic database does not give the reason (i.e. diagnosis) that led to the antibiotic prescription, some of the variables available in this database (Additional file 1: Table 1) were selected as inclusion criteria to obtain a patient typology as close as possible to that of a woman with uncomplicated UTI:

- Female sex (exclusion of men and unknown sex);

- Age between 20 and 59 years (age $>65$ years may be a risk factor for UTI complications, according to the French recommendations [19]);

- Living in France;

- The selected antibiotics were identified using the fifth level (i.e. chemical substances) of the ATC classification and their presentation ID code (to select only oral antibiotics).

Among the 25 different types of prescribers available in this database (Additional file 1: Table 1), two categories were selected: general practitioners (GPs) and secondary care physicians (including emergency services and physicians/GPs working in private clinics and residential care homes). These physicians are the most accessible and appropriate for the management of uncomplicated UTIs; these two categories alone account for more than $90 \%$ of all prescriptions.

\section{Statistical analysis}

The French healthcare system and particularly the modalities for prescribing and dispensing drugs did not allow us to use the daily defined dose to describe antibiotic consumption. Therefore, we used the number of boxes of a specific antibiotic dispensed by community pharmacies per year. Indeed, the database counts the deliveries per patient over a year in a binary way $($ no $=0$ / yes $\geq 1$ ), regardless of the number of boxes dispensed to that patient during that year $(1$ episode $=1$ delivery $/ 5$ episodes $=1$ delivery). Moreover, the delivery of two boxes of the same antibiotic type does not imply that a patient took all the tablets contained in the two boxes (e.g. pivmecillinam). Similarly, the delivery of four boxes of the same molecule does not imply that the four boxes were used to treat a single episode (e.g. fosfomycin).

The various analyses focused on the number of boxes of the main antibiotics indicated for UTI delivered by community pharmacies for each year and the prescriber type.

\section{Results}

Changes in antibiotic delivery from 2014 to 2019

Overall, the number of antibiotic boxes commonly used for UTI treatment and dispensed by community pharmacies (Fig. 1A) increased by 6\% from 2014 to 2018 (3, 984,834 boxes prescribed in 2014 and 4,227,236 in 2018), and then slightly decreased from 2018 to 2019 (4, 056,035 prescribed boxes in 2019), resulting in a $2 \%$ increase during the study period. However, this relative stable trend hid differences among antibiotic classes (Fig. 1B). Specifically, the prescription of pivmecillinam, an antibiotic that is now recommended as second-line treatment, progressively and rapidly increased $(+434 \%$ in $2015,+4107 \%$ in $2017,+7430 \%$ in $2019 ; 6000$ boxes were delivered in 2014 and more than 467,000 in 2019). The delivery of fosfomycin (the first-line drug for uncomplicated UTI) also progressively increased, but more slowly (+ 9\% in $2015,+28 \%$ in 2017 , and $+41 \%$ in 2019 ). On the other hand, the delivery of lomefloxacin and norfloxacin strongly decreased, particularly in $2019(-82 \%$ and $-88 \%$, respectively, compared with 2014). Ciprofloxacin and ofloxacin consumption showed a smaller decrease $(-26 \%$ and $-30 \%$, respectively, in 2019 compared with 2014), while nitrofurantoin delivery remained stable $(-0.6 \%)$ during the study period.

GPs were the most common prescribers of antibiotics for UTI management (76\% of all antibiotic prescriptions for UTI; approximately 4.2 million antibiotic boxes per year counted by the French National Health Insurance system), followed by secondary care physicians (16\% of all antibiotic prescriptions). These two categories alone were responsible for more than $92 \%$ of all prescriptions.

\section{Changes in antibiotics delivered depending on the Prescriber's type}

To evaluate the implementation of the 2015 UTI recommendations, the prescribing patterns of GPs and secondary care physicians were investigated (Fig. 2). During the study period, their prescribing behavior changed in line with the national recommendations, but some differences could be observed between GPs (Fig. 2A) and secondary care physicians (Fig. 2B).

Fosfomycin remained the most prescribed molecule, and its delivery by community pharmacies increased over time $(+39 \%$ for GPs and $+74 \%$ for secondary care physicians between 2014 and 2019). Conversely, the prescription of pivmecillinam, which is now recommended as a second-line treatment, increased more among GPs than secondary care physicians (respectively $+8207 \%$ and $+3913 \%$ ). However, nitrofurantoin prescription frequency did not change in both groups. Ciprofloxacin and ofloxacin were preferentially prescribed by secondary care physicians than by GPs. In 2019, these two molecules appeared in $37 \%$ of secondary care physicians' 

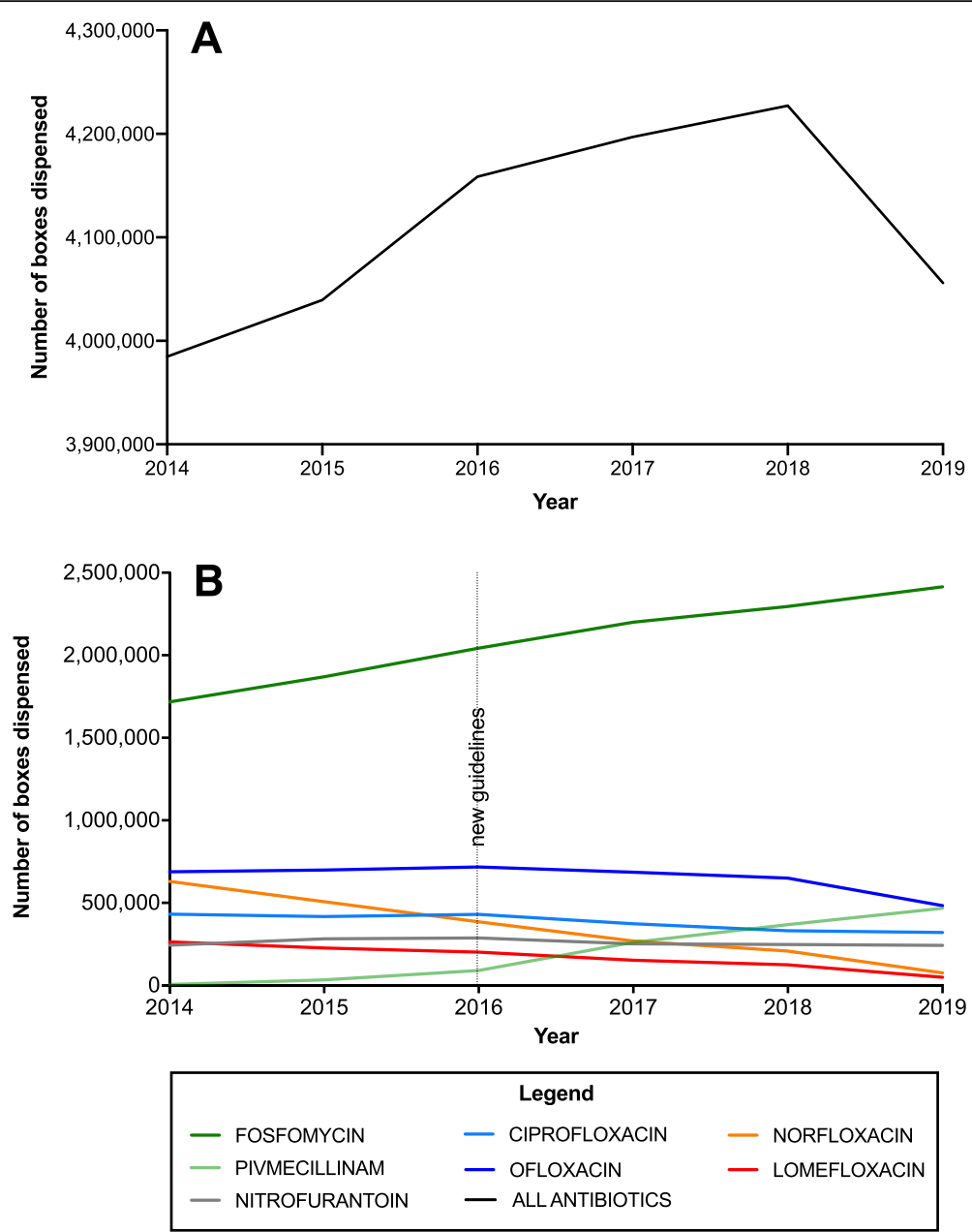

Fig. 1 Changes in antibiotic consumption, in France, between 2014 and 2019. a Overall consumption (assessed as number of boxes dispensed by community pharmacists per year) of the main antibiotic classes used for UTI management (fosfomycin, pivmecillinam, nitrofurantoin, ciprofloxacin, ofloxacin, norfloxacin, and lomefloxacin); b Temporal changes in the delivery by community pharmacists of the indicated antibiotics used for acute uncomplicated UTI

prescriptions and in $18 \%$ of GPs' prescriptions. Conversely, lomefloxacin and norfloxacin, which are no longer reimbursed since June 2019, were more frequently prescribed by GPs than secondary care physicians. In 2014, they represented 27 and $9 \%$ of all molecules prescribed by GPs and secondary care physicians, respectively. In 2019, they represented only 4 and $2 \%$ of all prescriptions by GPs and secondary care physicians, respectively.

Overall, the main trends observed in Fig. 1 (increase in 2018 before a decrease in 2019) were also detected for the antibiotic prescribing behaviors of GPs $(+3 \%$ between 2014 and 2019), but not of secondary care physicians $(+18 \%$ for the same period).

\section{Discussion}

\section{Main results}

The OpenMedic data, which reflect the antibiotic delivery by community pharmacies, showed variations according to the molecule class and the prescriber considered. We observed the emergence of pivmecillinam, an increase of fosfomycin, and a large decrease of norfloxacin and lomefloxacin prescriptions. This very large decrease, more than $80 \%$, for lomefloxacin and norfloxacin is an accomplishment on its own. Although the nonreimbursement of these molecules was implemented only at the end of the study period (in 2019), their prescription progressively decreased since the beginning of the study (in 2014). As the French national health authority opinion to end their reimbursement was issued in February 2017, we can hypothesize that these two years allowed prescribers to be informed about the decision, and to get acquainted with the new recommendations $[25,26]$. In addition, in France, most patients do not need to pay for their medications at the community pharmacy because the Health Insurance System pays directly the pharmacists. Therefore, they may not 

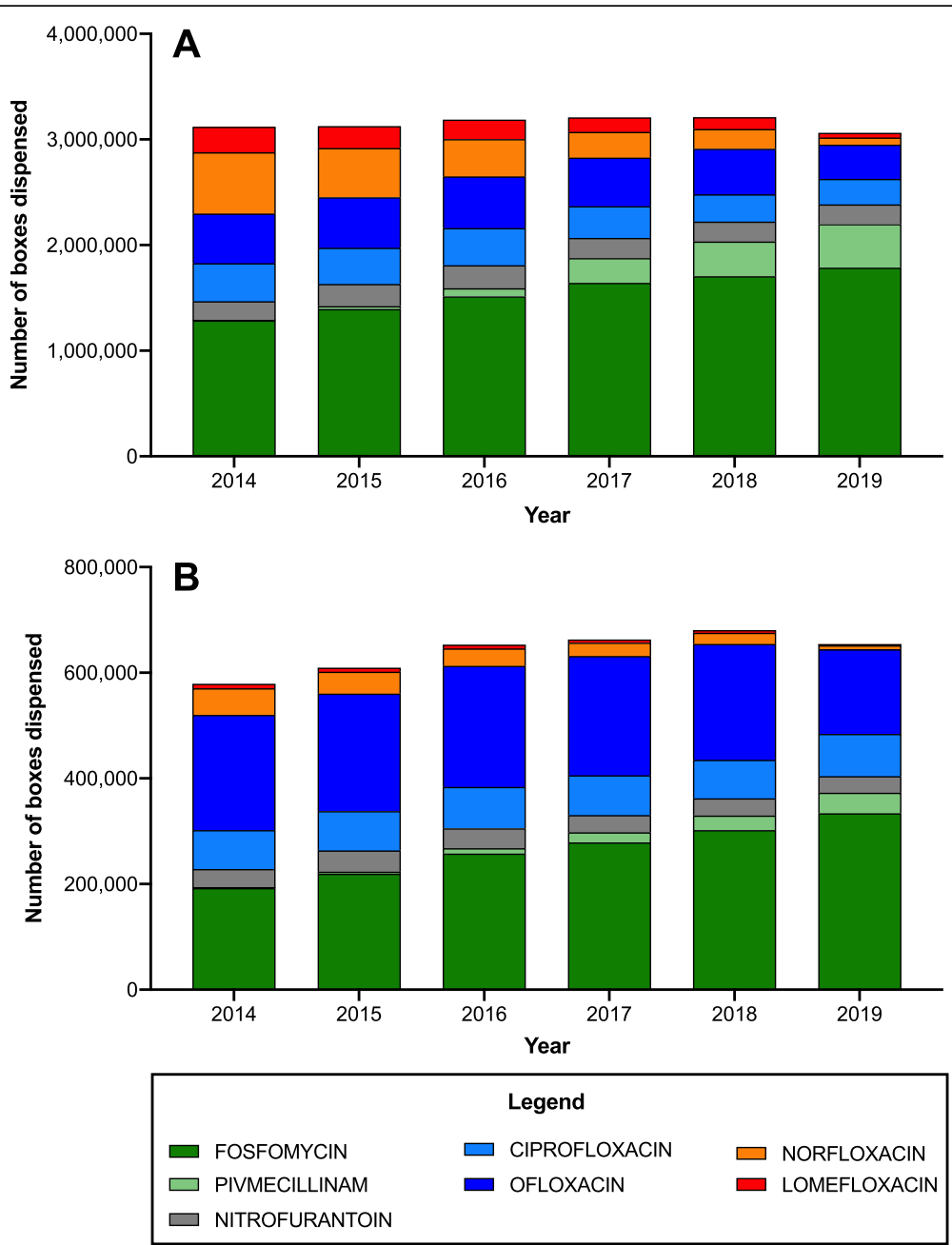

Fig. 2 Changes in antibiotics delivered by community pharmacies in France, between 2014 and 2019, according to the prescriber type: (a) General practitioners; (b) Secondary care physicians

understand and accept to pay for an antibiotic prescribed by a physician for UTI. As a consequence, they may refuse to buy the antibiotic, they may go to another physician, or they may ask the pharmacist to contact the prescriber in order to change the prescribed antibiotic molecule [27].

Some molecules were more specific to a specific prescriber. For example, pivmecillinam was prescribed mainly by GPs, and ofloxacin by secondary care physicians. In 2019, about 16\% of fosfomycin prescriptions were by secondary care physicians who are working in centers in which the resources and technical facilities are not designed to manage acute uncomplicated UTI. This could mirror the increase in the use of the emergency department even for minor health problems, particularly during weekends and weeknights (i.e. when GPs are often not on duty in France) [5, 28, 29]. Indeed, such prescriptions were mainly issued in a hospital, but the antibiotic was dispensed by a community pharmacy.
The finding about the high percentage of fluoroquinolone (ciprofloxacin, ofloxacin) prescriptions by secondary care physicians should also be considered with caution because they are prescribed for many infections that are often more serious than UTI. Moreover, the recommendations for other common infectious diseases were not changed during the study period. For instance, the latest recommendations for adult lower respiratory tract infections were published in 2010 [30] and for upper respiratory tract infections in 2011 [31]. Conversely, the proportion of pivmecillinam prescriptions increased in both groups but much more in the GP group. Overall, these differences can be explained by the fact that uncomplicated UTIs are, in theory, managed by GPs, while complicated infections are treated in hospital and do not have the same recommendations and treatments $[7,15]$.

\section{Impact of expert recommendations and health policies}

The study by Grol et al. focused specifically on the most effective ways to implement new scientific evidence in 
the daily medical practice [32]. Many tools are available for policymakers and practitioners, but no method seems to perform better than the others. Therefore, the choice of tool should be based on the specific environment and the health professionals targeted by the new recommendations/changes. Moreover, such tool should also allow regularly assessing the impact of the new measures.

The year 2016, when the new recommendations were implemented, was characterized by the strong increase in the delivery of pivmecillinam, which officially entered the therapeutic arsenal, and the significant decrease of ciprofloxacin. However, as the physicians' adherence to recommendations is poor, policymakers should combine the publication of new guidelines with interventions to convince prescribers [24, 33-37]. For example, in England, to reduce inappropriate UTI management, and to limit the risk of trimethoprim resistance, the National Health Service introduced the 'Quality Premium' program in 2016 with the aim of reducing trimethoprim prescriptions through financial incentives [38]. Similarly, the French health authorities concluded that lomefloxacin and norfloxacin have insufficient medical value and decided to stop their reimbursement at the beginning of 2019 to limit their use. This measure seems to be useful, as indicated by the very strong decrease in their delivery in 2019 and was supported by a broad-based communication (scientific congresses, websites and newsletters) to promote the new recommendations. For example, some very synthetic 'memos', including the key messages of the new recommendations were proposed [19].

The Infectious Diseases Society of America introduced new guidelines for UTI treatment in 2011 [39]. To measure compliance with these new recommendations, a retrospective analysis was carried from 2009 to 2013. The authors observed a positive change in the choice of antibiotic class. Conversely, the new guidelines did not seem to improve the inappropriate duration of antibiotic therapy. According to the authors, antimicrobial stewardship (AMS) interventions are needed to improve antibiotic prescribing for uncomplicated UTIs. AMS initiatives are regularly deployed in hospitals to prevent AMR. An AMS strategy implemented in emergency departments in Ohio, United States of America, was based on a two-step intervention [40]: i) an electronic order set based on the most recent guidelines for UTI treatment, with a financial incentive for its use, followed by ii) an audit and feedback. The first step of this AMS intervention led to a significant increase in the adherence to guidelines (from 44 to $68 \%$ ) that continued to increase to $82 \%$ after the second step.

How to improve the implementation of recommendations Besides the application of recommendations in terms of drug choice, it is important also to use the most adapted care pathway. Indeed, acute cystitis should be managed only by GPs and community pharmacists. However, uncomplicated UTIs are still a frequent reason to visit emergency departments $[28,41]$.

Moreover, all physicians, and particularly GPs should be aware of the need to comply with the latest recommendations to reduce AMR [42]. One of the keys to the successful implementation of new recommendations is knowledge transfer, and many solutions are already available [43]. For example, a computerized decision support platform can be a tool to translate complex healthcare knowledge into everyday practice [44]. A study evaluated the impact of a mobile phone application to increase guideline adherence by prescribers caring for inpatients with community-acquired pneumonia or urinary tract infections [45]. The authors observed an increase in the adherence to the antibiotic guidelines, but only for pneumonia management. Nonetheless, this type of tool seems to work for prescribers. Indeed, 145 health workers downloaded the application during the study period, and more than 3000 downloads were recorded several months later. In France, several quick and simple computer tools (e.g. Antibioclic $\odot$ and Vidal $\left.\operatorname{Recos}^{\ominus}[46,47]\right)$ are already available to find the recommended care pathway and most suitable treatment.

Some barriers need to be overcome. Communication, especially between GPs and institutions, is an important point [48]. Scientific societies and institutions have to work with physicians to make these recommendations more "userfriendly". Physicians could be included in the groups involved in guideline drafting to make them accessible to all and as close as possible to the real practice conditions. All the main concerned parties (clinicians, researchers, knowledge users, and institutions) should be brought together to identify common challenges and success factors for the implementation of a new program [49].

More than insufficient knowledge, lack of agreement with the recommendations and lack of applicability seem to be the main barriers to guideline adherence [50]. To overcome these barriers, education sessions could be proposed where small groups of GPs (or other healthcare professionals) can analyze their current practices and find ways to include the new recommendations [37, 40]. This approach is useful, but possibly not in the long term [51].

Several studies have assessed the impact of AMS in hospital settings, but very few in communities [52-55]. A recent article examined specifically AMS interventions in the community [56], and again, found that educationfocused interventions seem to be efficient to limit AMR. They also highlighted the lack of research on this topic in communities.

A systematic review in English primary care tried to identify ways to optimize AMS interventions [57]. The 
authors identified 41 types of influences on antibiotic prescribing that were categorized in six theoretical domains frameworks. To improve guideline implementation, they suggested, for example, electronic decision support tools, workshops on antibiotic prescribing, and implementing evidence-based practice protocols. They stressed that these types of AMS interventions should be implemented also in other primary care settings, such as community pharmacies.

Moreover, the collaboration between physicians and community pharmacists could be strengthened, particularly when they work in the same community. The pharmacist could contribute to optimize the prescription of antibiotics for UTIs and help to limit unnecessary antibiotic exposure [5860]. Different quality indicators (e.g. dosage, duration, antibiotic/antibiogram suitability) were improved after a pharmacist's intervention (>96\% of conformity for treatment duration and $98 \%$ for posology) [58].

\section{Limitations}

The lack of knowledge on the diagnosis is one of the biggest limits of this study. Despite the inclusion criteria based on sex and age, we cannot be sure that the delivered antibiotics were prescribed for UTI, although some of them (e.g. fosfomycin) should be used only for acute uncomplicated UTI in women. Moreover, the lack of information on the diagnosis did not allow checking the relevance of the antibiotic prescriptions. Therefore, antibiotics that can be used also for other indications were restricted to oral forms only, by eliminating all deliveries of ocular, auricular and injectable formulations.

The analysis of the number of boxes dispensed did not allow knowing the number of UTI episodes per year. Some treatments, for an episode, requires two boxes of antibiotics (pivmecillinam) and in other cases, the antibiotic can be used continuously for the prevention of recurrent cystitis (fosfomycin). Therefore, this analysis was based on an exhaustive result. The number of consumers, also available in this database, induced other biases (if a woman had three UTI episodes in the same year and was treated with the same antibiotic, she would have been counted only as one consumer). Data on the daily defined doses instead of the number of boxes would improve accuracy, and also allow comparing the French data with those of other countries.

Only the antibiotics recommended for UTI were selected, but others are prescribed to treat UTI (e.g. trimethoprim-sulfamethoxazole). Moreover, a drug dispensed in a pharmacy may be not taken by the patient for different reasons, including negative results of the urine culture. Finally, the non-reimbursement of lomefloxacin and norfloxacin from 2019 may have led to underreporting of their dispensing (if pharmacists do not submit the invoice to Health Insurance).
Another limitation concerns the database. As variables are limited, particularly the age groups ( $0-20$ years, 20 60 years, more than 60 years), we could not assess differences in antibiotic prescriptions to women of different ages. It would be relevant to have narrower age classes for future analyses.

\section{Future research}

It should be important to code each medical procedure to allow a more detailed and objective analysis of antibiotic prescription practices and adherence to recommendations [14, 38, 61]. The knowledge of the diagnosis should also be useful for community pharmacists to check the antibiotic prescription appropriateness.

Besides, it would be interesting to follow a cohort of patients to analyze their care pathway (category of practitioners, time required to receive the diagnosis and treatment, etc.) to identify and propose strategies to improve adherence to healthcare guidelines.

\section{Conclusion}

To limit AMR, the French authorities reviewed their recommendations for UTI management in 2015 and fluoroquinolones are now only recommended as a last resort for uncomplicated infection. The new recommendations seem to be increasingly followed, on the basis of the changes in the delivery of antibiotics recommended for UTI treatment: an increase of fosfomycin and pivmecillinam, and a decrease of fluoroquinolones.

However, there is still place for improvement. Health policymakers must encourage and promote adherence to such recommendations. Financial motivations, audits and feedback, educational interventions, implication of primary healthcare professionals, prescriber-pharmacist collaborations are among the many resources available to help physicians. These approaches are particularly useful in primary care, where most patients go for UTI and where the potential is high to significantly limit AMR.

\section{Abbreviations}

AMR: Antimicrobial resistance; AMS: Antimicrobial stewardship; ATC: Anatomical Therapeutic Chemical; GP: General practitioner; UTI: Urinary tract infections; WHO: World Health Organization

\section{Supplementary Information}

The online version contains supplementary material available at https://doi. org/10.1186/s12913-021-06653-4.

Additional file 1: Table 1: Variables available in the 'OpenMedic'

database*

\section{Acknowledgements}

This study is part of the French network of University Hospitals HUGO ('Hôpitaux Universitaires du Grand Ouest'). 


\section{Authors' contributions}

AP analyzed and interpreted the data. ARR interpreted the data and was a major contributor in writing the manuscript. SF, KGN and JFA have substantively revised the work. All authors read and approved the final manuscript.

\section{Funding}

Not applicable.

\section{Availability of data and materials}

The datasets analyzed in the present study are available in the 'OpenMedic' database that collects data from the Système National des données de santé (National Health Data System), https://www.data.gouv.fr/fr/datasets/openmedic-base-complete-sur-les-depenses-de-medicaments-interregimes/

\section{Declarations}

\section{Ethics approval and consent to participate}

Not applicable.

\section{Consent for publication}

Not applicable.

\section{Competing interests}

The authors declare that they have no competing interests.

\section{Author details}

'Univ Angers, Inserm, CNRS, MINT, SFR ICAT, 16 boulevard Daviers, F-49000 Angers, France. ${ }^{2}$ Department of Urology, Technical University of Munich, Munich, Germany. ${ }^{3}$ Department of Urology, Pediatric Urology and Andrology, Justus-Liebig University of Giessen, Giessen, Germany. " Faculté de Santé, Département de Médecine Générale, Univ Angers, F-49000 Angers, France. ${ }^{5}$ Univ Angers, Univ Rennes, EHESP1, Inserm, IRSET-ESTER, SFR ICAT, F-49000 Angers, France.

Received: 10 February 2021 Accepted: 14 June 2021

Published online: 28 June 2021

\section{References}

1. Foxman B. Epidemiology of urinary tract infections: incidence, morbidity, and economic costs. Am J Med. 2002;113(1):5-13. https://doi.org/10.1016/ S0002-9343(02)01054-9.

2. Geerlings SE. Clinical presentations and epidemiology of urinary tract infections. Microbiol Spectr. 2016;4(5). https://doi.org/10.1128/microbiolspec. UTI-0002-2012.

3. Société de pathologie infectieuse de langue française. Deuxième conférence de consensus en thérapeutique anti-infectieuse. Médecine Mal Infect. 1990:20:620-3.

4. The European Association of Urology. XVth Congress of the European Association of Urology. Brussels, Belgium, April. Eur Urol. 2000;37 Suppl 2:1175.

5. Elkharrat D, Arrouy L, Benhamou F, Dray A, Grenet J, Corre AL. Épidémiologie de l'infection urinaire communautaire de l'adulte en France. In: Lobel B, Soussy C-J, editors. Les infections urinaires. Paris: Springer Paris; 2007. p. 1-20. https://doi.org/10.1007/978-2-287-48617-3_1.

6. Bruyère F, Boiteux J-P. Épidémiologie, diagnostic et traitement des cystites aiguës isolées ou récidivantes de l'adulte. EMC Urol. 2011;4(3):1-11. https:// doi.org/10.1016/S1762-0953(11)50629-6.

7. Société de pathologie infectieuse de langue française. Diagnostic et antibiothérapie des infections urinaires bactériennes communautaires de l'adulte. 2015. http://www.infectiologie.com/UserFiles/File/spilf/recos/ infections-urinaires-spilf-argumentaire.pdf. Accessed 27 Dec 2018.

8. World Health Organization, editor. Antimicrobial resistance: global report on surveillance. Geneva, Switzerland: World Health Organization; 2014.

9. Bell BG, Schellevis F, Stobberingh E, Goossens H, Pringle M. A systematic review and meta-analysis of the effects of antibiotic consumption on antibiotic resistance. BMC Infect Dis. 2014;14(1):13. https://doi.org/10.11 86/1471-2334-14-13.

10. World Health Organization, editor. Global action plan on antimicrobial resistance. 2015. https://apps.who.int/iris/handle/10665/193736. Accessed 21 Jul 2020.
11. World Health Organization. Global antimicrobial resistance and use surveillance system (GLASS) report - Early implementation 2020. 2020. https://apps.who.int/iris/bitstream/handle/10665/332081/9789240005587eng.pdf?ua=1. Accessed 20 Oct 2020 .

12. IACG. No time to wait: Securing the future from drug-resistant infections. Report to the Secretary-General of the United Nations. 2019. https://www. who.int/antimicrobial-resistance/interagency-coordination-group/IACG_fina I_report_EN.pdf?ua=1. Accessed 20 Oct 2020.

13. Little P, Merriman R, Turner S, Rumsby K, Warner G, Lowes JA, et al. Presentation, pattern, and natural course of severe symptoms, and role of antibiotics and antibiotic resistance among patients presenting with suspected uncomplicated urinary tract infection in primary care: observational study. BMJ. 2010;340(feb05 1):b5633. https://doi.org/10.1136/ bmj.b5633.

14. Sigler M, Leal JE, Bliven K, Cogdill B, Thompson A. Assessment of appropriate antibiotic prescribing for urinary tract infections in an internal medicine clinic. South Med J. 2015;108(5):300-4. https://doi.org/10.14423/ SMJ.0000000000000278.

15. Gupta K, Hooton TM, Naber KG, Wullt B, Colgan R, Miller LG, et al. International clinical practice guidelines for the treatment of acute uncomplicated cystitis and pyelonephritis in women: a 2010 update by the Infectious Diseases Society of America and the European Society for Microbiology and Infectious Diseases. Clin Infect Dis. 2011;52(5):e103-20. https://doi.org/10.1093/cid/ciq257.

16. G. Bonkat (Chair), R. Bartoletti, F. Bruyère, T. Cai, S.E. Geerlings, B. Köves, S. Schubert, F. Wagenlehner, Guidelines Associates: W. Devlies, J. Horváth, G. Mantica, T. Mezei, A. Pilatz, B. Pradere, R. Veeratterapillay. EAU Guidelines: Urological Infections. Uroweb. https://uroweb.org/guideline/urologicalinfections/\#1. Accessed 21 Jul 2020

17. Bader MS, Loeb M, Brooks AA. An update on the management of urinary tract infections in the era of antimicrobial resistance. Postgrad Med. 2017; 129(2):242-58. https://doi.org/10.1080/00325481.2017.1246055.

18. AFSSAPS. Diagnostic et antibiothérapie des infections urinaires bactériennes communautaires chez l'adulte. Médecine Mal Infect. 2008:38:S203-52.

19. Haute autorité Santé. Cystite aiguë simple, à risque de complication ou récidivante de la femme. 2016. https://www.has-sante.fr/portail/upload/ docs/application/pdf/2016-11/v1-fm_cystite_aigue_cd-151116.pdf. Accessed 27 Dec 2018.

20. European Commission. A European one health action plan against antimicrobial resistance. 2017. https://ec.europa.eu/health/amr/sites/health/ files/antimicrobial_resistance/docs/amr_2017_action-plan.pdf. Accessed 21 Jul 2020.

21. Ministère des Solidarité et de la Santé, editor. National health strategy 20182022. 2017. https://solidarites-sante.gouv.fr/IMG/pdf/dossier_sns_2017_ synthesev6-10p_anglaisv2.pdf.

22. Maugat Sylvie, Berger-Carbonne Anne. Consommation d'antibiotiques et résistance aux antibiotiques en France : une infection évitée, c'est un antibiotique préservé ! 2018. https://www.santepubliquefrance.fr/content/ download/186827/2320191. Accessed 21 Jul 2020.

23. Caisse nationale de l'assurance maladie. Open Medic : base complète sur les dépenses de médicaments interrégimes. https://www.data.gouv.fr/fr/data sets/open-medic-base-complete-sur-les-depenses-de-medicamentsinterregimes/. Accessed 21 July 2020.

24. Agut S. Prise en charge déclarée des cystites aiguës simples et récidivantes par les médecins généralistes français: étude de l'adéquation aux recommandations publiées par la SPILF en 2014. Paris Descartes; 2017. https://dumas.ccsd.cnrs.fr/dumas-01701036/document.

25. Dufay $\mathrm{A}$. The repercussion of stopping reimbursement of olmésartan on antihypertensive drugs prescription and blood pressure control of treated hypertensive patients in France. Ann Cardiol D'Angéiologie. 2018;67(3):149_ 53. https://doi.org/10.1016/j.ancard.2018.04.024.

26. Humbert X, Rabiaza A, Schonbrodt L, Raginel T, Le Bas F. Impact du déremboursement de l'olmésartan chez les patients hypertendus en soins premiers. Ann Cardiol Angéiologie. 2020;69(3):139-43. https://doi.org/10.101 6/j.ancard.2020.03.018.

27. França LR, Vidal C, Bourechak N, Jeunne PL, Deville GS-C, Massol J. A cohort study of therapeutic prescriptions after the end of phytotherapy drug reimbursement by French social security. Pharmacoepidemiol Drug Saf. 2013;22(7):760-8. https://doi.org/10.1002/pds.3382.

28. Le Conte $P$, Elkharrat $D$, Potel G. Prise en charge des infections urinaires communautaires dans les Service d'Accueil et d'Urgence Français. 
Antibiotiques. 2004;6(4):237-9. https://doi.org/10.1016/S1294-5501(04)942707.

29. Elkharrat D, Brun-Ney D, Cordier B, Goldstein F, Péan Y, Sanson-Le-Pors MJ, et al. Prescriptions d'antibiotiques dans 34 services d'accueil et de traitement des urgences français Antimicrobial drugs prescribing in 34 french emergency department. Médecine Mal Infect. 2003;33(2):70-7. https://doi.org/10.1016/S0399-077X(02)00008-2.

30. Agence Française de Sécurité Sanitaire des Produits de Santé. Antibiothérapie par voie générale dans les infections respiratoires basses de l'adulte. Pneumonie aiguë communautaire. Exacerbations de bronchopneumopathie chronique obstructive. Médecine Mal Infect. 2010; 41:221-8.

31. Société de pathologie infectieuse de langue française. Antibiothérapie par voie générale en pratique courante dans les infections respiratoires hautes de l'adulte et l'enfant. Argumentaire. Médecine Mal Infect. 2011;35:578-618.

32. Grol R, Grimshaw J. From best evidence to best practice: effective implementation of change in patients' care. Lancet. 2003;362(9391):1225-30. https://doi.org/10.1016/S0140-6736(03)14546-1.

33. Llor C, Rabanaque G, Lopez A, Cots JM. The adherence of GPs to guidelines for the diagnosis and treatment of lower urinary tract infections in women is poor. Fam Pract. 2011;28(3):294-9. https://doi.org/10.1093/fampra/cmq1 07.

34. Kabbara WK, Meski MM, Ramadan WH, Maaliki DS, Salameh P. Adherence to international guidelines for the treatment of uncomplicated urinary tract infections in Lebanon. Can J Infect Dis Med Microbiol J Can Mal Infect Microbiol Médicale. 2018;2018:1-6. https://doi.org/10.1155/2018/7404095.

35. Zatorski C, Zocchi M, Cosgrove SE, Rand C, Brooks G, May L. A single center observational study on emergency department clinician non-adherence to clinical practice guidelines for treatment of uncomplicated urinary tract infections. BMC Infect Dis. 2016;16(1):638. https://doi.org/10.1186/s12879-01 6-1972-6.

36. Taur Y, Smith MA. Adherence to the Infectious Diseases Society of America guidelines in the treatment of uncomplicated urinary tract infection. Clin Infect Dis. 2007:44(6):769-74. https://doi.org/10.1086/511866.

37. Grover ML, Bracamonte JD, Kanodia AK, Bryan MJ, Donahue SP, Warner A-M, et al. Assessing adherence to evidence-based guidelines for the diagnosis and Management of Uncomplicated Urinary Tract Infection. Mayo Clin Proc. 2007:82(2):181-5. https://doi.org/10.1016/50025-6196(11)60996-8.

38. Croker R, Walker AJ, Goldacre B. Why did some practices not implement new antibiotic prescribing guidelines on urinary tract infection? A cohort study and survey in NHS England primary care. J Antimicrob Chemother. 2019;74(4):1125-32. https://doi.org/10.1093/jac/dky509.

39. Durkin MJ, Keller M, Butler AM, Kwon JH, Dubberke ER, Miller AC, et al. An assessment of inappropriate antibiotic use and guideline adherence for uncomplicated urinary tract infections. Open Forum Infect Dis. 2018;5(9). https://doi.org/10.1093/ofid/ofy198.

40. Hecker MT, Fox CJ, Son AH, Cydulka RK, Siff JE, Emerman CL, et al. Effect of a stewardship intervention on adherence to uncomplicated cystitis and pyelonephritis guidelines in an emergency department setting. PLoS One. 2014;9(2):e87899. https://doi.org/10.1371/journal.pone.0087899.

41. Sondik EJ, Madans JH, Sadagursky MH, Madans JH, Hunter EL, Sisk JE, et al. Ambulatory care visits to physician offices, hospital outpatient departments, and emergency departments: United States, 2001-02. Vital Health Stat. 2006;13:1-73.

42. Butler CC, Hillier S, Roberts Z, Dunstan F, Howard A, Palmer S. Antibioticresistant infections in primary care are symptomatic for longer and increase workload: outcomes for patients with E.coli UTIs. Br J Gen Pract. 2006; 56(530):686-92.

43. Pappano D, Conners G, Mclntosh S, Humiston S, Roma D. Sources of knowledge transfer among primary care pediatric health care providers. Clin Pediatr (Phila). 2008;47(9):930-4. https://doi.org/10.1177/0009922808320600.

44. Abidi S, Vallis M, Piccinini-Vallis H, Imran SA, Abidi SSR. Diabetes-related behavior change knowledge transfer to primary care practitioners and patients: implementation and evaluation of a digital health platform. JMIR Med Inform. 2018;6(2):e25. https://doi.org/10.2196/medinform.9629.

45. Yoon CH, Ritchie SR, Duffy EJ, Thomas MG, McBride S, Read K, et al. Impact of a smartphone app on prescriber adherence to antibiotic guidelines in adult patients with community acquired pneumonia or urinary tract infections. PLoS One. 2019;14(1):e0211157. https://doi.org/10.1371/journal. pone.0211157.
46. Antibioclic: Antibiothéraphie rationnelle en soins primaires. https://a ntibioclic.com/. Accessed 16 Sep 2020.

47. VIDAL - Recommandations. https://www.vidal.fr/recommandations/. Accessed 4 Nov 2020.

48. Slade SC, Kent P, Patel S, Bucknall T, Buchbinder R. Barriers to primary care clinician adherence to clinical guidelines for the Management of low Back Pain: a systematic review and Metasynthesis of qualitative studies. Clin J Pain. 2016;32(9):800-16. https://doi.org/10.1097/AJP.0000000000000324.

49. Ahmed S, Ware P, Visca R, Bareil C, Chouinard M-C, Desforges J, et al. The prevention and management of chronic disease in primary care: recommendations from a knowledge translation meeting. BMC Res Notes. 2015;8(1):571. https://doi.org/10.1186/s13104-015-1514-0.

50. Lugtenberg M. Guidelines on uncomplicated urinary tract infections are difficult to follow: perceived barriers and suggested interventions. BMC Fam Pract. 2010;11(1):51. https://doi.org/10.1186/1471-2296-11-51.

51. Willems L, Denckens P, Philips H, Henriquez R, Remmen R. Can we improve adherence to guidelines for the treatment of lower urinary tract infection? A simple, multifaceted intervention in out-of-hours services. J Antimicrob Chemother. 2012;67(12):2997-3000. https://doi.org/10.1093/jac/dks336.

52. Chavada R, Davey J, O'Connor L, Tong D. "Careful goodbye at the door": is there role for antimicrobial stewardship interventions for antimicrobial therapy prescribed on hospital discharge? BMC Infect Dis. 2018;18(1):225. https://doi.org/10.1186/s12879-018-3147-0.

53. Tang SJ, Gupta R, Lee Jl, Majid AM, Patel P, Efird L, et al. Impact of hospitalist-led interdisciplinary antimicrobial stewardship interventions at an Academic Medical Center. Jt Comm J Qual Patient Saf. 2019;45(3):207-16. https://doi.org/10.1016/j.jcjq.2018.09.002.

54. Toma M, Davey PG, Marwick CA, Guthrie B. A framework for ensuring a balanced accounting of the impact of antimicrobial stewardship interventions. J Antimicrob Chemother. 2017;72(12):3223-31. https://doi. org/10.1093/jac/dkx312.

55. Hecker MT, Son AH, Murphy NN, Sethi AK, Wilson BM, Watkins RR, et al. Impact of syndrome-specific antimicrobial stewardship interventions on use of and resistance to fluoroquinolones: an interrupted time series analysis. Am J Infect Control. 2019;47(8):869-75. https://doi.org/10.1016/j.ajic.2019.01. 026.

56. Lam TT, Dang DA, Tran HH, Do DV, Le H, Negin J, et al. What are the most effective community-based antimicrobial stewardship interventions in lowand middle-income countries? A narrative review. J Antimicrob Chemother. 2021;76(5):1117-29. https://doi.org/10.1093/jac/dkaa556.

57. Borek AJ, Wanat M, Atkins L, Sallis A, Ashiru-Oredope D, Beech E, et al. Optimising antimicrobial stewardship interventions in English primary care: a behavioural analysis of qualitative and intervention studies. BMJ Open. 2020;10. https://doi.org/10.1136/bmjopen-2020-039284.

58. Rochefolle A, Maison O, Chazaud C, Rioufol C, Rode G, Luaute J, et al. Impact des interventions pharmaceutiques sur l'antibiothérapie des infections urinaires en service de soins de suite et de réadaptation. Prog En Urol. 2017;27(7):439-45. https://doi.org/10.1016/j.purol.2017.04.007.

59. Zhang X, Rowan N, Pflugeisen BM, Alajbegovic S. Urine culture guided antibiotic interventions: a pharmacist driven antimicrobial stewardship effort in the ED. Am J Emerg Med. 2017;35(4):594-8. https://doi.org/10.1016/j.a jem.2016.12.036.

60. Gendrin V, Letranchant L, Hénard S, Frentiu E, Demore B, Burty C, et al. Amélioration de la prescription des fluoroquinolones dans les infections urinaires. Revue de pertinence à deux tours. Presse Med. 2012;41(1):e10-4. https://doi.org/10.1016/j.lpm.2011.05.013.

61. Romero LY, Lopez AH, Araujo DF, Lara MM, Marquez-Gomez I. 4CPS-063 appropriateness of antibiotic prescribing in urinary tract infections in the emergency department of a tertiary hospital. Eur J Hosp Pharm. 2018. 25(Suppl 1):A70-1.

\section{Publisher's Note}

Springer Nature remains neutral with regard to jurisdictional claims in published maps and institutional affiliations. 